\title{
Exploring the Misalignment between Business and Information Technology on the Implementation of Balanced Scorecard: Case Study of State-Owned Telecommunication Companies in Indonesia
}

\author{
Hardy Santosa Sundoro* \\ School of Business and Management, \\ Institut Teknologi Bandung \\ Bandung, West Java, 40132, Indonesia \\ hardy-santosa@sbm-itb.ac.id
}

\author{
Harimukti Wandebori \\ School of Business and Management, \\ Institut Teknologi Bandung \\ Bandung, West Java, 40132, Indonesia \\ harimukti@sbm-itb.ac.id
}

\begin{abstract}
Many organizations around the world have faced misalignment in attaining the alignment between business and Information Technology (IT). The positive effect of alignment on overall company success has been focused on previous research. On the other hand, the misalignment in the implementation of a balanced scorecard was primarily unexplored. This study aimed at identifying and evaluating the factors that contribute to a misalignment of

businesses and IT. The case study methodology is conducted in two state-owned telecommunication companies in Indonesia. The telecommunication industry's selection as the case study is because of their nature closely related to technology development and implementation. Five semi-structured interviews, field notes and business records are used to produce the data, which have been thematically analyzed and further follow by cross-case analysis to compare the thematic analysis result from each company. This study has resulted in 12 factors of misalignment between business and IT that can inhibit achieving alignment in

implementing a balanced scorecard. The main findings showed that human factors, enterprise architecture, and IT project implementation factors could be three main source themes that can potentially contribute to misalignment. The findings may allow researchers to devise frameworks for how misalignments can be minimized to align business and IT better. This finding also useful in practice for companies that are seeking to achieve business-IT alignment by focusing on human factors, enterprise architecture factors, and IT project implementation factors.
\end{abstract}

Keywords: Misalignment, business-IT alignment, IT strategy, Balanced Scorecard, a stateowned telecommunications company

\section{Introduction}

The Society for Information Management's (SIM) annual Chief Information Officers (CIOs) surveys has consistently placed the IT alignment amongst the top three challenges by Information Technology (IT) managers since 2009. The new 2019 SIM survey also listed IT alignments as the third big concern

* Corresponding Author 
or worry field of CIOs, with responses from 1033 IT executives representing 618 organizations and 376 CIOs (Kappelman et al. 2019). For over 20 years, many researchers have tried to overcome this gap and introduce various framework steps to reach a better business-IT alignment. Past findings suggested that some factors exist impeding business and IT alignment. One solution to improve business-IT alignment is to recognize management activities that hinder business-IT alignment (Luftman and Brier 1999).

Therefore, to better understand the business-IT problem, it is necessary to know the factors that cause misalignment between business and IT. It becomes important because if the company can identify the list of misalignment factors, then the management, which includes business and IT, can fix it to help the business achieve its business goals. Luftman (2000) points out that the fulfilment and persistence of alignment demand optimize enablers and eliminates alignment inhibitors. Without a complete understanding of the factor that can cause misalignment between business and IT, the company will find difficulties in achieving alignment. Studies on factors that cause misalignment have not yet studied empirically, especially within the Indonesian context (Chan and Reich 2007; Leonard and Seddon 2012).

Our study's starting point is that the misalignment factors between business and IT remain fragmented in the literature. In the literature, we found that three main sources cause misalignment between business and IT. There are human factors (Corsaro and Snehota 2011; Dulipovici and Robey 2013; Handley 2017; Leonardi 2009), enterprise architecture factors (Alhassan and Ochoche 2013; Fichman and Melville 2014; Ori 2017a), and IT project implementation factors (Heath et al. 2013; Soh and Sia 2004; Wei et al. 2005). Previous studies on misalignment have focused on either human factors, enterprise architecture factors, or IT project implementation factors. This fragmented misalignment factor theme and remained unclear on pointing put what sub-factors contributing to the misalignment in the literature will only look at misalignment as a standalone theme without considering that it is better to see all three misalignment factor themes as a comprehensive framework for understanding business-IT complexity alignment.

Therefore, this research has focused on combining the three main source of misalignment factor fragmented in the past literature to be the comprehensive framework for exploring the misalignment factors between business and IT on implementing a balanced scorecard. We are exploring the misalignment using a comprehensive framework that includes human factors, enterprise architecture factors, and IT project implementation factors to understand misalignment as a whole system better. This study's main objective is to explore the misalignment factors between business and IT that inhibit achieving alignment on balanced scorecard implementation in two state-owned telecommunication companies in Indonesia.

\section{Literature Review}

\section{Human Factors as a Misalignment Source}

Concerning human factors, misalignments will occur when workers perceive the IT resources and their strategic role in the organization differently (Dulipovici and Robey 2013). Human factors suggest companies' need to verify that there are sufficient verification procedures to identify misalignment that might occur (Corsaro and Snehota 2011). Also, misalignment can occur due to social interaction differences, especially in using or implementing new technology between business and IT. Leonardi (2009) added that how new technology is interpreted among employees focuses on the social interaction that can cause possible misalignment. Another human factor that can also cause misalignment is the incapacity of IT employees while doing a job. For example, in relationship with the outsourcing of information management activities implemented by administrators, the expertise in which workers will work IT can influence outsourcing efficiency and the connection to corporate governance (Handley 2017). Additionally, Chief Executive Officers (CEOs) and IT executives' skills of understanding the new technology are also considered critical in achieving business-IT alignment (Coltman et al. 2015). 


\section{Enterprise Architecture as Misalignment Source}

Enterprise architecture (EA) contains many business processes, IT structures and application systems (Alhassan and Ochoche 2013). Enterprise architecture applies architectural concepts and practices to drive companies around the improvements in business, method, and technology required to enforce their strategies. EA is a critically beneficial feature since it has many advantages, such as increased business agility, reduced business \& IT risks and cost management. However, it implicitly complicates business goals, which presents a challenge for many CIOs and Chief Technology Officers (CTOs) seeking to create a consistent connection between EA and business goals. Misalignment arises where the company does not implement the appropriate EA to meet business needs (Ori 2017b). The company act to an IT innovation can also contribute to the misalignment between business and IT. If the company does not react to IT innovation, it cannot achieve its competitive advantage in the digital era (Fichman and Melville 2014).

\section{IT Project Implementation as a Misalignment Source}

For the IT project implementation issue, the main emphasis is on the lack of comprehension of what the business intends with what IT employees do about the business strategy. For instance, when the business manager and IT employee have different views about something that should be defined as done when creating a business project solution, there is likely misalignment. Also, the IT project implementation misalignment can occur when there is a mismatch between the company's existing IT core infrastructure with the expected results from the business side (Heath et al. 2013). In another research from Wei, Wang and Ju (2005), they give an example in their research that the misalignment can occur because of disruptive transformation by launching a new system between an Enterprise Resource Planning (ERP) system's implementation. From a systemic standpoint, business-IT misalignment could occur due to conflicting IT activities with other divisions (Soh and Sia 2004). Their research gave an example that misalignment is most likely to arise if any IT project is forced to be implemented by management and IT by not allowing all employees to accept that new IT implementation.

\section{The IT Balanced Scorecard}

Since Kaplan and Norton introduced a balanced Scorecard in 1998, the concept has been applied to other departments in the company, with no exception to the IT department. However, since the nature of the IT acts as internal service support inside the company, Martinsons, Davison and Tse (1999) proposed the perspectives and measures suggested by Kaplan and Norton to be considerably adjusted. The customised four perspectives for an IT Balanced Scorecard (IT BSC) were proposed by Martinsons, Davison and Tse (1999): Customer Perspectives becomes User Orientation, Financial Perspective becomes Business Value or Corporate Contribution Perspective, Internal Business Perspective becomes Operational Excellence, and Learning and Growth Perspective becomes Future Readiness. Kaplan and Norton also emphasize the value of sticking three principles to translate the strategy into action. These principles consist of building cause-effect-linkages, choosing appropriate performance drivers, and providing a linkage to financial measures (Kaplan and Norton 1996).

\section{Research Methodology}

The case study method was chosen for this study. A case study is well adapted for studying the complexity of processes in natural environments (Benbasat et al. 1987; Yin 1984) and the rich dynamics of a particular environment (Eisenhardt 1989). Case study research is aimed to develop a theory that includes validity strength (Eisenhardt 1989). It is designed to fulfil the need to maximize the research quality through validity and reliability (Yin 1984). In this study, validity and reliability tests were done using the selected case study tactics. The construct validity was applied by using multiple sources of evidence. The internal validity procedure was established to ensure an underlying theory used in the study. The underlying theory was used for the thematic analysis and cross-case analysis technique. If possible, the external validity process would be applied to generalize the research findings in a different context. However, in this study, the external validity relied on theory in two case studies. The reliability 
procedure was performed to make that the study's result could be reproduced under a similar methodology. To increase the reliability and to reduce bias in data collection, a case description was prepared for the case organization in a case study setting. A protocol was developed to test the reliability of the case study research.

The complexity of their administrative systems, operations, services, and accessible information makes the business-IT alignment demanding for large corporations. Consequently, it was also essential to select a large corporation to get an in-depth analysis and view of misalignment factors. For this research, the case study was conducted at two of the state-owned telecommunication companies in Indonesia. It has been deemed eligible for this research because it is a multinational corporation and has a complicated company hierarchy structure. It fulfils the International Standard Industrial Classification criteria of all Economic Activities' regulations for large businesses with more than 100 employees (UN 2008). Also, the telecommunication companies were chosen because their business is very closely related to technology. Hence, we assume that the company should be more aware of the new technology used for business transformation. The selection was also based on the condition that both companies have the same business in the telecommunication sector. Their IT department also acts as an enable and driver for business. Hence, we assume that the company should be more aware of the new technology used for business transformation. The detail about the company profile describes below:

Company A is one of the Indonesian state-owned enterprises engaged in telecommunications, which has served as the leading supplier for developing the national telephone network for more than three decades. Since the convergence trend between telecommunication technology and information technology, Company A has changed business orientation from being based initially on pure manufacture to an industry based on system solutions, particularly in information and communication systems and technology integration. The company was considered fit for the case study because IT become the core of the business. IT acts as a driver and enablers for business to achieve a portfolio that the company wants, especially in the digital service and system integrator portfolio. It also can be seen from the organizational structure that places the IT department under the business directorate.

Company $\mathrm{B}$ is a state-owned enterprise engaged in the telecommunications and network services sector in Indonesia. The company has significant businesses in fixed-line telephony, internet and data communications. The company grew up with more than 24.000 employees in 2019. With fast-growing and robust business in digital and telecommunication, the company has a mission to grow and sustain its digital service innovation with an agile and robust network and IT infrastructure.

Interviews were deemed the most effective method to obtain practical experience, in-depth insight and more information in specific, nuanced ways, pursuing the research issue that demanded interaction with numerous interviewees from various positions. The interview structure questions addressed in this research were based on the literature review presented in section two concerning misalignment factors. For this research, five interviewees from two state-owned telecommunication companies were chosen. Related to the number of interviewees, then it is related to data saturation. Saunders et al. (2018) conclude that it might be better to think about rich and dense data rather than the sample size. The best way to distinguish between rich and thick data is to think of rich as quality and thick as quantity. Rich data is multi-layered, intricate, informative, complicated, and more than thick data. One can have much dense data, but not a lot of it, or one can have a lot of rich data but not a lot of it. Therefore, to ensure data saturation and validity, the researcher conducted purposive sampling. Each interviewee was selected based on their knowledge and directly engaged in creating and executing business and IT strategies and affecting business and IT alignment. It is aligned with (Yin 1984) that the interviewees should be closely linked to the research subject and familiar with the research field. The list of the interviewee and other information are presented in Table 1.

An analysis of case studies shows that case studies using several evidence sources have, as far as their overall quality is concerned, been rated more highly than studies using only one data source (Yin 1984). In this study, the triangulation used consisted of three triangulation types: data or source triangulation, theory triangulation, and methodological triangulation. Triangulation of data or sources in this study will focus more on using different informants to show consistency in the misalignment factors found in the company. These different informants were obtained by interviewing employees of different levels. 
There are differences in position and seniority, including top management (such as vice president) and middle manager (project manager or IT manager). Data triangulation was conducted until the researcher got complete data and found saturated data validation from the source. So, it could be the source to find the result and conclusion. The researcher expected that with this technique, collected data could fulfil the conclusions construct.

Table 1. Interviewee information

\begin{tabular}{|l|l|l|c|c|}
\hline Company & Interviewees & Job responsibilities & Interview Date & $\begin{array}{l}\text { Interview } \\
\text { duration (min) }\end{array}$ \\
\hline $\begin{array}{l}\text { Company } \\
\text { A }\end{array}$ & $\begin{array}{l}\text { Interviewee } \\
\text { (I1) }\end{array}$ & $\begin{array}{l}\text { Vice President of } \\
\text { Information Technology } \\
\text { (VP of IT) }\end{array}$ & 67 \\
\hline $\begin{array}{l}\text { Company } \\
\text { A }\end{array}$ & $\begin{array}{l}\text { Interviewee } \\
\text { (I2) }\end{array}$ & $\begin{array}{l}\text { Information Technology } \\
\text { Infrastructure Manager }\end{array}$ & $2020-06-04$ & 54 \\
\hline $\begin{array}{l}\text { Company } \\
\text { B }\end{array}$ & $\begin{array}{l}\text { Interviewee } \\
\text { (I3) }\end{array}$ & $\begin{array}{l}\text { Executive General Manager } \\
\text { Information Technology } \\
\text { (EGM of IT) 2020-04-28 }\end{array}$ & 37 \\
\hline $\begin{array}{l}\text { Company } \\
\text { B }\end{array}$ & $\begin{array}{l}\text { Interviewee } \\
\text { (I4) }\end{array}$ & $\begin{array}{l}\text { Manager of IT Planning and } \\
\text { Architecture 2020-05-20 }\end{array}$ & 36 \\
\hline $\begin{array}{l}\text { Company } \\
\text { B }\end{array}$ & $\begin{array}{l}\text { Interviewee 5 } \\
\text { (I5) }\end{array}$ & $\begin{array}{l}\text { Senior Manager of C/FU } \\
\text { Support and ITSM }\end{array}$ & $2020-06-10$ & 65 \\
\hline
\end{tabular}

Then, using archival documents obtained from each company, the methodological triangulation process is also carried out by matching the misalignment factors obtained from interviews with the company documents under study. From Company A, the researcher received seven documents. Meanwhile, from Company B, the researcher received eight documents. With the existence of company documents that support the respondent's statement, the misalignment factor results can further explain the misalignment phenomenon that occurs. Finally, theory triangulation is carried out by explaining theories regarding misalignment factors that come from previous research. This theory triangulation process also aims to compare the findings in the form of factors that cause misalignment with the relevant perspective theory. Researchers are expected to avoid the researcher's bias. It will result in the process of generalization and validity of the data generated.

The thematic analysis in this study has been seen as more relevant for discovering new perspectives on the research subject. As for coding technique, the coding be done manually. The guidelines for the thematic analysis in terms of manual coding proposed by Braun and Clarke (2006) with the steps as following: (1) familiarizing with the data; (2) generating initial codes; (3) searching for themes; (4) reviewing themes; (5) defining and naming themes; and (6) producing the report. Therefore, the process began with the reading of transcribed interviews, internal documents and other documents to get general insights. In this research, after we generated the thematic analysis based on each company's alignment conditions, we compared the two case studies to articulate a chain of reasoning for the differences and similarities in each case study's results. By analyzing each case before comparing various cases, the researcher can detect specific patterns of cases, thereby deepening his understanding of the cases and facilitating cross-case comparisons (Sato 2016). Here, the researcher tries to describe in detail the events, processes, or stages of each case that originate from direct interviews with respondents and observations. Each detail of the incident is written along with excerpts from interviews with respondents to strengthen the empirical evidence. In supporting validity and reliability, comparisons with previous studies as a process of triangulation will be presented so that it is found that solid theoretical explanations support the misalignment factors that occur. Cross-case analysis enhances the researchers' ability to understand how relations between discrete cases can exist, accumulate actual knowledge, refine and develop concepts (Ragin 1997), and build or test theory (Eckstein 2002). However, due to 
the limitation of the pages for this research, the results in this section will be shown in cross-case analysis result as the final result for showing the misalignment factors found in this study.

\section{Results and Analysis}

\section{Human Factors as a Misalignment Source}

\section{Business-IT Communication Only Happen at the Top-Level Management}

At Company A, communication is not structured through the formal channel when involving employees but mainly flows through informal networks. Formal communication only occurs in business directorate meetings and board meetings. It has resulted in disseminating information regarding the business strategy that will only rotate at the top management.

"Where am I going to speak? There are two media that can be used, internal business directorates and board meetings.” (Interviewee 1)

On the other hand, at Company B, to communicate business directions that will be carried out and develop ideas from employees, the business strategy explanation process is carried out by the Vice President of IT, then packaged in two-way communication with the IT employee.

"The IT division has events, for example, Leader Talks Value, where VP of IT explained or gave a presentation to all of his IT division employees when it was not a pandemic. VP of IT conveyed strategic matters that need to be shared with each employee. That is one example of a training process for disseminating strategic programs' socialization, and there are several other methods. So, the point is that there is a top-down socialization mechanism at the bottom level of employee." (Interviewee 5)

The misalignment factor found in this study is consistent with past research, which found that the communication gap between business and IT is the main reason why the misalignment factors happen (Alaceva and Rusu 2015; Alghazi et al. 2020; El-Mekawy et al. 2015; Ullah and Lai 2013). According to Sauer \& Yetton (1997), the basic concept is that IT should maintain communication to represent the business's management needs. In a nutshell, alignment is a way of strengthening coordination between corporate leaders who make strategic decisions and IT employee who control technical operations.

\section{Lack of Business Executive Visionary}

Without a clear view of corporate direction, CIOs and IT managers often perceive run IT organizations as cost centres. As a result, alignment remains one of the top IT management issues (Kappelman et al. 2019). It also happened to Company A, where the board of directors did not yet have clear directions regarding how IT could provide significant changes for the company's profits.

"So, from the business, we do not know the business roadmap". (Interviewee 1)

The company's strategic plan that has been made in the form of nine core competence directives that must be mastered is useless because there is no further definition of the target market for the product that is being made.

"It is true that we have entered into digital service but which digital service that we enter in then has not been defined. The current digital service at Company A only supports all internal lines. When talking about digital service, there are so many branches, which have not been defined." (Interviewee 1)

On the other hand, IT Executives at Company B always try to get a vision related to IT technology that would drive business through research elsewhere. One of the ways is holding gatherings with vendors related to the latest technology that can be applied in the company to support the company going forward.

"I started, of course, from CSS (Corporate Strategic Scenario), but i is not enough; CSS is just an initiative business. I also have to research in other places for the technology that can support CSS. As a business initiative, we follow CSS, but I have to research elsewhere if it is related to technology. I 
have my partner as a reference, including many vendors. Therefore, we conduct gathering with our vendors. It means that I need to know what latest technology or upgrades I need to adopt for the company?" (Interviewee 3)

This study's misalignment factor is compatible with previous studies, which showed that a business executive often made IT choices with no IT experience, potentially causing the corporation to be misaligned (Gerow et al. 2014; Ullah and Lai 2013). IT awareness is essential to business management because few resources in every company, and IT expenditure are typically expensive with a high risk of failure. This IT knowledge includes the prospective and shortcomings of the enterprise's IT technology, the use of IT by competitors, and the prospects for new technology to increase business (Chedrawi and Howayeck 2019). The lack of business executive visionary in Company A is also because they are not well informed with the standard best practices that should be looked at to achieve the competitive advantage such as Gartner. They have not overlooked Gartner as the best industry practices to be implemented as their future investment. Again, it contrasts with Company B when the business executive is exposed to the next technology in the next five years. Company B's business executive uses the Gartner as the guideline for achieving competitive advantage results for the next 3 or 5 years.

\section{Lack of Business Executive Commitment}

Without a top management sponsor, likely, that initiative in a company will not be achieved. Niven (2005) emphasizes that the top management initiative is crucial for implementing the balanced scorecard. He claims that if the BSC program is not sponsored by top management and its position in addressing actual problems is not acknowledged, it will produce poor results and fail. Company A's vision and mission are outlined in a strategic plan in the form of nine core competencies. However, in practice, the Board of Directors does not commit to creating nine core competencies, causing managers to feel astonished and question the board of directors' commitment.

"So sometimes I feel a little confused too. Because the company's vision and mission are posted on websites everywhere, right? It means that when the vision has been approved, it means we all have to go there. It must be aligned." (Interviewee 2)

At Company A, this made the VP of IT angry and often questioned Company A core competence which had never been upgraded. As time went on, he gave up on the BOD decision while still trying to remind him of the directorate meeting.

"I know that there are nine core competencies that we have to create for our employee and our business in the future. I already convinced them that we have to develop our nine core competencies that have been formulated, but if they do not want to, then it is ok." (Interviewee 1)

This study's misalignment factor is consistent with past research, which found that insufficient management commitment towards IT planning will give rise to misalignment between business and IT (Lucke et al. 2010; Luftman et al. 1999; Seppänen et al. 2009). IT's strategic value is influenced by executives' commitment to IT investments and IT's corporate productivity role (Neirotti and Paolucci 2007). Thus, fail to commit to IT planning will therefore influence the business strategy. Furthermore, "the greater the commitment of top management, the greater effectiveness of IT Governance" (Buchwald et al. 2014). Solid and committed management promotes IT governance development by specific organizational guidance or strategies (Willson and Pollard 2009). It is further stressed by highlighting the importance of top-level management commitment to IS issues and initiatives, such as getting a business sponsor while preparing IT projects (Stoel and Muhanna 2012).

\section{Lack of transfer knowledge from senior IT to junior}

At Company A, the misalignment factor is also caused by the large number of senior employees who will soon retire so that the knowledge transfer process does not run smoothly. This process begins with an employment gap between seniors and juniors due to employee recruitment that has stopped for several years. 
"Because many of our employees have retired, want to retire, or will retire, then the transfer of knowledge from them to juniors is too far away. It was also coupled with the recruitment process that has stopped for several years. So, when there is a gap too far, then it makes transferring knowledge difficult." (Interviewee 2)

The misalignment factor found in this study is supported by past research that found that knowledge sharing barriers will impact the company's performance (Qureshi and Evans 2015; Santos et al. 2012; Veer Ramjeawon and Rowley 2017). Levy (2011) and Wong (2009) even state that knowledge loss is a severe threat. The danger in the baby-boomers retirement is that they take away their knowledge, experience and vital skills about managing and handling IT projects. Knowledge of the older employees cannot easily be replaced because they acquired much different knowledge and their expertise is closely connected to themselves over the years of their working life. Implementing a structured program to transfer vital information is one way to counteract this challenge (Maruta 2012). It is not possible to collect and transmit all information, but that is not the aim. The goal is to pass only the essential organizational information specific to the job, which would jeopardize an organization's ability to function if lost.

\section{Low Level of IT Education and Certification}

The effect of a low level of IT education and certification is intensely felt in terms of getting IT-related projects. Some certifications can even be a tender requirement that will facilitate the company's credibility to win the tender project. However, the certification process is not an obligation formulated by Company A. The IT Manager later regretted this.

"The certification will only be obliged when there is a tender that we want to get. When there is a project or tender that requires certification in RKS (Work Plan and Conditions) document, for example, the requirement is that one engineer has certification in network, for example, CCIE (The Cisco Certified Internetwork Expert). If that is the case, then the certification will be mandatory to take." (Interviewee 2)

The misalignment factor found in this study is consistent with past research, which found that lack of IT skills results in the misalignment occur between a business and IT (Alghazi et al. 2018; Carañana et al. 2016; Coltman et al. 2015; El-Mekawy et al. 2015; Kurti et al. 2013; Weiss and Anderson 2004). Weiss \& Anderson (2004) concluded that the failure to develop, sustain and get the necessary expertise is a significant obstacle in aligning business and IT. Research from El-Mekawy et al. (2015) also stated that a low level of IT understanding and knowledge cause uncertainty on business strategies towards IT. According to Alghazi et al. (2018), if there is no concrete strategy to develop IT employees expertise to fulfil the organization's needs, the desired IT strategic results would not be realized. As a result, IT personnel must be sophisticated enough to communicate with upper management while also mastering the technology needed for IS production and deployment (Poon and Wagner 2001). IT employees would be encouraged to bring in better and more appropriate technology change plans to promote company goals and strategies as they keep up with technological developments.

\section{Limited Number of IT Employees}

When comparing the thematic analysis of the two case studies in Company A and Company B, we discovered that having a small number of IT employees causes misalignment, as seen in Company A, where only 12 employees work in the IT operation division and the remainder work in the product development section. This number is not ideal, so the board of directors wants to increase the number of IT employees to 50 people. With the limited number of IT employees, there are several functions that one person must concurrently hold. This condition is different from Company B, where the number of IT employees is adjusted to the level of company needs. Because the information technology division at Company B makes many in-house applications, the developer and the IT service desk team's composition is balanced. With the number of IT employees reaching 180 people in company B, one employee can focus on their field. It is also strengthened by the company's technical career path with certification according to its type of expertise and position. 
This study's misalignment factor is supported by past research that found that the limited number of IT employees influences business and IT's alignment process (Wang \& Rusu, 2018). Wang \& Rusu (2018) conducted a study on three SMEs in China and found that due to limited IT employees, request for IT application improvement from business managers was ignored because IT personnel were too busy to respond to the business manager's requests. Consequently, according to research from Chesley (2014), multitasking on the job doing by an employee will impact the employee to be stressed in their workplace. Interruptions are well-known to be harmful to work, and other investigations have indicated a link between interruptions and multitasking with decreased employee health (Jett and George 2003; Mark et al. 2008). Therefore, it is necessary to plot the number of IT employees according to the company's needs and the required expertise of these IT employees.

\section{Enterprise Architecture as Misalignment Source}

1. There is a gap between the employees' core competencies and the technological developments that must be mastered

In Company A, the VP of IT said a gap between IT technology changing so fast with employee's core competence. It is exacerbated by businesses that do not see the core competencies that must be owned. The VP of IT also said that aligning difficulties occurred when the Company's Long-Term Plan was not final and was not formulated in a detailed and structured manner.

If we want to examine the competencies that we already have, perhaps only at least two core competencies that we have, but for big data, IoT, Artificial Intelligence, we still do not have yet. Even though the business wants us to go in that direction, well, this is difficult in realigning because even in the company's long-term plans, the strategy is not final yet and no direction towards what we should going to do." (Interviewee 1)

The misalignment factor discovered in this study is reinforced by previous studies that find that IT staff's inability to keep up with innovations would preclude IT from converting business requirements into technological solutions (Krotov 2015; Kurti et al. 2013). As a result, the existence of a gap between IT employees' core competencies and the technology they must master makes IT employees feel frustrated and unable to provide support and advice related to IT technology to support business strategies in achieving competitive advantage. It adds to a tense relationship between business and IT executives, making it more challenging to grasp business and technological demands and requirements (Alaceva and Rusu 2015).

\section{The Strategy is not Illustrated in Strategy Map}

The strategy map is a Balanced Scorecard method to represent the strategy in cause-effect linkages. The strategic outcomes and performance drivers are core elements of the strategy map. For KPIs development, the strategy map should be the foundation. Without a strategy map, the employee will not follow the KPI's or participate in them. There is a risk that too many KPIs will evolve and cause uncertainty in such circumstances if KPIs are generated without a clear understanding of each other (Othman 2009). IT Executive in Company B admitted that this was a problem because due to the absence of a strategy map, productivity measurement could not be measure and only based on the feeling that the IT division had an impact and contribution.

"We have many certifications and training, but when we talk about the effect of certification and training on our productivity seems that we do not have yet. We feel the intrinsic presence of the activities that we did, but when asked to prove it by showing the relationship, then we do not have it." (Interviewee 3)

The misalignment factor observed in this study is reinforced by previous studies, which has shown that the lack of capacity to quantify IT contributions to the company leads to misalignment (Majstorovic 2016; Wang and Rusu 2018). Nfuka \& Rusu (2013) also argue that merely making business and IT plans is inadequate. Business-IT alignment needs to provide and coordinate business-IT strategies to cascade them down in an enterprise. To fill this gap, IT leadership is needed to align enterprise technology architecture with business strategies. 


\section{Not Implement Appropriate Enterprise Architecture}

The failure to adopt the latest enterprise architecture to support the business has allegedly played an essential role in supporting its business continuity in the future. Companies that catch up with the latest technology and implement them correctly can make significant changes in transforming a company's business. It is as emphasized IT Executive in Company B.

"The business has shifted from cooper to voice and now to the internet era. When I saw that the existing IT infrastructure and the applications that we have are no longer match, we have to modernize our IT core system." (Interviewee 3)

This study's misalignment factor is consistent with past research that found that business strategy that was not supported sufficiently by their IT systems will result in misalignment (Hussin et al. 2002). Many researchers and practitioners have stressed the importance of aligning business and IT strategies. It has often been acknowledged that a company's failure to capitalize on information technology (IT) may significantly impact its sustainability and viability (Besson and Rowe 2012; Ilmudeen et al. 2019).

\section{IT Project Implementation as a Source of Misalignment}

\section{IT Project Overpromises}

An IT executive has noted that one of the mistakes is to overpromise IT programs launched. At the start of the project, IT people are expected to be optimistic and offer a positive IT capability overview.

"The execution level exactly as you discussed earlier is not as beautiful as planned. In this sense, the timeline regarding the master plan time sometimes does not go smoothly. IT is unique, and it means that not everything we imagine has been done well. There are many dynamics, that is why there is CSS in Company B. Even though we have a 5-year work plan, we have to roll the term every year, we review it, resetting alignment again." (Interviewee 3)

This study's misalignment factor is consistent with past research, which found that overpromising when the beginning of IT project will cause the misalignment (Alaceva and Rusu 2015; Bloch et al. 2012; Lagerström et al. 2011; Pinto 2013). Lagerström et al. (2011) found out that in many situations, there seems to be a perception that IT Projects are struggling to provide the promised benefits to the company because they cannot be implemented efficiently and cheaply enough. According to their results, project managers are frequently expected to prepare for the project and provide the customer with an estimation of how long the project will take and how much it will cost. It means they must be skilled at calculating the project's duration and expense. Overpromising is a common occurrence of project managers who, to appease the customer, pledge more than they can achieve.

\section{Low Demonstration of IT Value}

In company A, the low perceived value of IT can cause misalignment between business and IT. The condition is that the business still does not see the value of IT. According to the interviewee in Company A, IT more frequently tends to solve the company's internal problem rather than bring attention to successful projects. In contrast, when looking at the Company A organizational structure where the IT department was put under the business directorate, which aimed to be a core of its business primarily to support Company A vision and mission portfolio.

"It is just sometimes like the project division is more prioritized rather than the IT department as a product development team. Even though we are in core or product development, we did not get too much attention." (Interviewee 2)

Past mistakes or successes in IT execution, on the other hand, will minimize or improve the potential to show IT value (El-Mekawy et al. 2015). It is just like what happened in Company B when the IT division succeeds to bring the sales increase in 2016 by developing a mobile application to request fibre optic instalment. As they already prove their work, IT's value in Company B increases and supports top management to develop and maintain its core infrastructure. It is also in line with Myers (1994) research, which suggests that the value of IT will achieve when an information system is perceived to 
be successful by stakeholders. Our studies share the same results as previous results from El-Mekawy et al. (2015) that highlighted the business department perceived low IT value because they still do not see IT's value but instead sees it as a cost. El-Mekawy et al. (2015) also noted that a one-sided partnership is one of the main reasons the misalignment occurs in the group because IT is not seen as a strategic partner by the business department.

\section{Low IT Budget}

VP of IT in Company A emphasizes that misalignment occurs because the company is in survival mode condition. It causes the company to prioritize short-term business sustainability with the risk that there will be a further gap in the future between developing technology and the core competencies of employees.

"When we talk about survival mode, there is only a small amount to be invested in the research budget.
Survival mode made our financial should be cut for developments." (Interviewee 1)

The misalignment factor found in this study is aligned with past research that found that lack of budget impacts business and IT alignment (Banaeianjahromi and Smolander 2017; El-Mekawy et al. 2015; Khan 2017). El-Mekawy et al. (2015) pointed out on their research the example of a company that still uses the ERP system developed in the late 90's due to the inflexibility of IT architecture related to cost. According to Khan (2017), the disruption of business-IT alignment is based on human and financial resources. A lack of any of the resources could lead to a misalignment of the two entities. To communicate with top management and keep up with the new technology, a high-quality IT staff is required (Poon and Wagner 2001). When available resources fail to achieve the desired outcomes, the resources must be reallocated, and a business-IT alignment must be created. It is necessary to keep human and financial support for the IT division since technology plays a central role in developing and capitalising on new business models. Thus, failure to keep up with the latest technology will cause the company to lose its competitive advantage towards business competition.

\section{Discussion}

The analysis has revealed 12 misalignment factors split into three major themes that could be identified into three major themes: human factors, enterprise architecture factors, and IT project implementation factors. The findings of this study fill significant gaps existing in business-IT alignment literature. From the alignment perspective, this study offers a more detailed view of the factors that inhibit alignment, which in turn affect business-IT alignment. The study reveals that misalignment factors cannot be only seen using one perspective of misalignment, but it needs to understand the whole understanding factors that can cause misalignment. The sub-factors identified in this study essentially confirm and significantly extend the earlier findings of several previous researchers. Simultaneously, we identified misalignment factors in this study (e.g., lack of transfer knowledge between senior and junior, the limited number of IT employees, the strategy is not illustrated in strategy map, there is a gap between the employee's core competencies and the technological developments that must be mastered) not much researched yet in the existing business-IT alignment literature.

By looking at the misalignment factors found in this study, we conclude that if these misalignment factors happen in a company, a perception will arise from the business department that IT is only wasting its investment. IT is not seen as a strategic partner that can help business departments achieve company goals but often perceived as a cost center. If they continue without any awareness of it, practices like this can cause the IT department's value to become less visible to the company. Instead of being an enabler or driver for a company to transform its business strategy, IT will only be seen as a department that only needs to focus on technical support without knowing how the business works. It will harm the entire organization because misalignment will hinder a company from achieving its competitive advantage by not maximizing the IT potential to transform the business. 


\section{Conclusion}

This research has two implications, namely academically and practically. In academic implications, this study has described 12 misalignment factors that can occur in implementing the balanced scorecard with empirical evidence from two state-owned telecommunications companies through in-depth case study methodologies. Therefore, this result expands the knowledge in business-IT alignment literature by providing the factors that must be identified to align business and IT better. Besides, this research is also helpful for great practical use because it will raise awareness for the business and IT management to check whether the factors presented in this study exist in each environment. Therefore, all factors must be carefully considered if the company wants to fully utilize the IT department's alignment to achieve its business goals.

This study has several limitations. First, there is a limited number of individuals interviewed. The data collection was collected during the first quarter of the Corona pandemic when many companies close their office. To overcome this situation, the researcher collects the interviewee using the insider in each of company. Therefore, the participants' determination in this study was using the purposive sampling technique, which is selecting participants according to the objectives and criteria previously determined by the researcher. It can be ascertained that the data obtained will be in accordance with the phenomenon under study. One of the interviewee's requirements is that they should have a job in managing and planning the alignment between business and IT.

Second, we only examine big companies. Meanwhile, because medium and small companies are not dynamic, misalignment can be different. Consequently, prospective studies should focus on examining the causes of misalignment in less complex structures. Furthermore, all of the interviewees were from senior managerial positions within their companies. Getting the views of other parties, such as alignment experts and staff, may explain specific problems. Third, the study's interpretation, findings, and applicability should be interpreted in the research context. Therefore, it may pose doubts in terms of generalizability in the statistical sense. Nevertheless, the findings' generalizability is discussed theoretically by linking the findings to previous research. Also, more research is needed to understand further how to minimize the impact of misalignment factors in the workplace. It is also better to quantitatively analyse the importance or weight of each misalignment factors in the company.

\section{References}

Alaceva, C., and Rusu, L. 2015. "Barriers in Achieving Business/IT Alignment in a Large Swedish Company: What We Have Learned?," Computers in Human Behavior (51), pp. 715-728.

Alghazi, A., Cui, T., Shen, J., Samuel, F. W., and Li, M. 2020. "A Qualitative Study of the Strategic Alignment Perspective of Public-Sector Organisations in Saudi Arabia in the Digitalisation Age," in Pacific Asia Conference on Information Systems.

Alghazi, A., Li, M., Cui, T., Samuel, F. W., and Shen, J. 2018. "Misalignment between Business and IT Strategic Objectives in Saudi Arabia Public Sector Organisations," in Proceedings of the 3rd International Conference on Internet of Things, Big Data and

Alhassan, M. E., and Ochoche, A. 2013. "The Role of Enterprise Architecture in Aligning Business and Information Technology in Organisations : Nigerian Government Investment on Information Technology," International Journal of Engineering and Technology (

Banaeianjahromi, N., and Smolander, K. 2017. "Lack of Communication and Collaboration in Enterprise Architecture Development," Information Systems Frontiers (21:4), pp. 877-908.

Benbasat, I., Goldstein, D. K., and Mead, M. 1987. "The Case Research Strategy in Studies of Information Systems," MIS Quarterly (11:3), pp. 369-386.

Besson, P., and Rowe, F. 2012. "Strategizing Information Systems-Enabled Organizational Transformation: A Transdisciplinary Review and New Directions," Journal of Strategic Information Systems (21:2), pp. 103-124.

Bloch, M., Blumberg, S., and Laartz, J. 2012. "Delivering Large-Scale IT Projects on Time, on Budget, and on Value," McKinsey on Business Technology.

Braun, V., and Clarke, V. 2006. "Using Thematic Analysis in Psychology," Qualitative Research in Psychology (3:2), pp. 77-101. 
Buchwald, A., Urbach, N., and Ahlemann, F. 2014. "Business Value through Controlled IT: Toward An Integrated Model of IT Governance Success and Its Impact," Journal of Information Technology (29:2), pp. 128-147.

Carañana, C. D., Ortiz, M. P., and Armengot, C. R. 2016. "What Are the Competences in Information System Required by Managers? Curriculum Development for Management and Public Administration Degrees," Technology, Innovation and Education.

Chan, Y. E., and Reich, B. H. 2007. "IT Alignment: What Have We Learned?, Journal of Information Technology (22:4), pp. 297-315.

Chedrawi, C., and Howayeck, P. 2019. "Artificial Intelligence a Disruptive Innovation in Higher Education Accreditation Programs: Expert Systems and AACSB," in ICT for a Better Life and a Better World (Vol. 30), pp. 115-129.

Chesley, N. 2014. "Information and Communication Technology Use, Work Intensification and Employee Strain and Distress," Work, Employment and Society (28:4), pp. 589-610.

Coltman, T., Tallon, P., Sharma, R., and Queiroz, M. 2015. "Strategic IT Alignment: Twenty-Five Years On," Journal of Information Technology (30:2), pp. 91-100.

Corsaro, D., and Snehota, I. 2011. "Alignment and Misalignment in Business Relationships," Industrial Marketing Management (40:6), pp. 1042-1054.

Dulipovici, A., and Robey, D. 2013. "Strategic Alignment and Misalignment of Knowledge Management Systems: A Social Representation Perspective," Journal of Management Information Systems (29:4), pp. 103-126.

Eckstein, H. 2002. "Case Study and Theory in Political Science," in Case Study Method Key Issues, Key Texts, London: Sage Publications.

Eisenhardt, K. M. 1989. "Building Theories from Case Study Research," Academy of Management Review (14:4), pp. 532-550.

El-Mekawy, M., Rusu, L., Perjons, E., Sedvall, K.-J., and Ekici, M. 2015. "Strategic and Tactical Business-IT Alignment Barriers in Organizations Acting in Sweden," International Journal of IT/Business Alignment and Governance (6:2), pp. 31-55.

Fichman, R., and Melville, N. 2014. "How Posture-Profile Misalignment in IT Innovation Diminishes Returns: Conceptual Development and Empirical Demonstration," Journal of Management Information Systems (31:1), pp. 203-240.

Gerow, J. E., Kearns, G. S., Thatcher, J. B., and Roth, P. L. 2014. "Looking Toward the Future of ITBusiness Strategic Alignment through the Past: A Meta-Analysis," MIS Quarterly (38:4), pp. $1159-1185$.

Handley, S. M. 2017. "How Governance Misalignment and Outsourcing Capability Impact Performance," Production and Operations Management (26:1), pp. 134-155.

Heath, D., Singh, R., and Shephard, B. 2013. "Approaching Strategic Misalignment from Organizational View of Business Processes," Proceedings of the Annual Hawaii International Conference on System Sciences, pp. 4055-4064.

Hussin, H., King, M., and Cragg, P. 2002. "IT Alignment in Small Firms," European Journal of Information Systems (11:2), pp. 108-127.

Ilmudeen, A., Bao, Y., and Alharbi, I. M. 2019. "How Does Business-IT Strategic Alignment Dimension Impact on Organizational Performance Measures: Conjecture and Empirical Analysis," Journal of Enterprise Information Management (32:3), pp. 457-476.

Jett, Q. T., and George, J. M. 2003. "Work Interrupted: A Closer Look at the Role of Interruptions in Organizational Life," Academy of Management Review (28:3), pp. 494-507.

Kaplan, R. S., and Norton, D. P. 1996. The Balanced Scorecard: Translating Strategy into Action, Boston: Harvard Business School Press.

Kappelman, L., McLean, E., and Johnson, V. 2019. "2020 Comprehensive Report: Results and Observations from the SIM IT Trends Study."

Khan, M. A. 2017. "Investigation of Critical Factors That Perturb Business-IT Alignment in Organizations," International Journal of Advanced Computer Science and Applications (8:5), pp. 133-137.

Krotov, V. 2015. "Bridging the CIO-CEO Gap: It Takes Two to Tango," Business Horizons (58:3), pp. 275-283.

Kurti, I., Barolli, E., and Sevrani, K. 2013. "Critical Success Factors for Business-IT Alignment: A 
Review of Current Research," Romanian Economic and Business Review (8:3), pp. 1-24.

Lagerström, R., Sommestad, T., Buschle, M., and Ekstedt, M. 2011. "Enterprise Architecture Management's Impact on Information Technology Success," 2011 44th Hawaii International Conference on System Sciences, pp. 1-10.

Leonard, J., and Seddon, P. 2012. "A Meta-Model of Alignment," Communications of the Association for Information Systems Volume (31:11).

Leonardi, P. M. 2009. "Why Do People Reject New Technologies and Stymie Organizational Changes of Which They Are in Favor? Exploring Misalignments Between Social Interactions and Materiality," Human Communication Research (35:3), pp. 407-441.

Levy, M. 2011. "Knowledge Retention: Minimizing Organizational Business Loss," Journal of Knowledge Management (15:4), pp. 582-600.

Lucke, C., Krell, S., and Lechner, U. 2010. "Critical Issues in Enterprise Architecting - A Literature Review," 16th Americas Conference on Information Systems 2010, pp. 1-11.

Luftman, J. 2000. "Assessing Business-IT Alignment Maturity," Communications of the Association for Information Systems (4).

Luftman, J., and Brier, T. 1999. “Achieving and Sustaining Business-IT Alignment," California Management Review (1), pp. 109-122.

Luftman, J., Papp, R., and Brier, T. 1999. "Enablers and Inhibitors of Business-IT Alignment," Communications of the Association for Information Systems (1).

Majstorovic, M. 2016. "Business and IT Alignment," Military Technical Courier (64:2), pp. 496-512.

Mark, G., Gudith, D., and Klocke, U. 2008. "The Cost of Interrupted Work: More Speed and Stress," in Proceedings of the SIGCHI Conference on Human Factors in Computing Systems, pp. 107110.

Martinsons, M., Davison, R., and Tse, D. 1999. "The Balanced Scorecard: A Foundation for the Strategic Management of Information Systems,” Decision Support Systems (25:1), pp. 71-88.

Maruta, R. 2012. "Transforming Knowledge Workers into Innovation Workers to Improve Corporate Productivity," Knowledge-Based Systems (30), pp. 35-47.

Myers, M. D. 1994. "Dialectical Hermeneutics: A Theoretical Framework for the Implementation of Information Systems," Information System Journal (5), pp. 51-70.

Neirotti, P., and Paolucci, E. 2007. "Assessing the Strategic Value of Information Technology: An Analysis on the Insurance Sector," Information and Management (44:6), pp. 568-582.

Nfuka, E. N., and Rusu, L. 2013. "Critical Success Framework for Implementing Effective IT Governance in Tanzanian Public Sector Organizations," Journal of Global Information Technology Management (16:3), pp. 53-77.

Niven, P. 2005. Balanced Scorecard Diagnostics: Maintaining Maximizing, New Jersey: John Wiley \& Sons.

Ori, D. 2017a. "On Exposing Strategic and Structural Mismatches Between Business and Information Systems," Corvinus University of Budapest.

Ori, D. 2017b. "Business-IT Misalignment Symptom Detection Based on Enterprise Architecture Analysis," Proceedings of the EEWC Forum 2017.

Othman, R. 2009. "How Balanced Scorecard Can Fail: Some Caves," Borneo Bulletin.

Pinto, J. K. 2013. "Lies, Damned Lies, and Project Plans: Recurring Human Errors That Can Ruin the Project Planning Process," Business Horizons (56:5), pp. 643-653.

Poon, P. P., and Wagner, C. 2001. "Critical Success Factors Revisited: Success and Failure Cases of Information Systems for Senior Executives," Decision Support Systems (30:4), pp. 393-418.

Qureshi, A. M. A., and Evans, N. 2015. "Deterrents to Knowledge-Sharing in the Pharmaceutical Industry: A Case Study," Journal of Knowledge Management (19:2), pp. 296-314.

Ragin, C. C. 1997. "Turning the Tables: How Case-Oriented Research Challenges Variable-Oriented Research," Comparative Social Research (16), pp. 27-42.

Santos, V. R., Soares, A. L., and Carvalho, J. Á. 2012. "Knowledge Sharing Barriers in Complex Research and Development Projects: An Exploratory Study on the Perceptions of Project Managers," Knowledge and Process Management (19:1), pp. 27-38.

Sato, H. 2016. "Generalization Is Everything, or Is It?: Effectiveness of Case Study Research for Theory Construction," Annals of Business Administrative Science (15:1), pp. 49-58.

Sauer, C., and Yetton, P. W. 1997. "The Right Stuff - An Introduction to New Thinking about 
Management," in Steps to Future Fresh Thinking on the Management of IT-Based Organizational Transformation 1st Ed, San Francisco: Jossey-Bass, pp. 1-21.

Saunders, B., Sim, J., Kingstone, T., Baker, S., Waterfield, J., Bartlam, B., Burroughs, H., and Jinks, C. 2018. "Saturation in Qualitative Research: Exploring Its Conceptualization and Operationalization," Quality and Quantity (52:4), pp. 1893-1907.

Seppänen, V., Heikkilä, J., and Liimatainen, K. 2009. "Key Issues in EA-Implementation: Case Study of Two Finnish Government Agencies," 2009 IEEE Conference on Commerce and Enterprise Computing, pp. 114-120.

Soh, C., and Sia, S. K. 2004. "An Institutional Perspective on Sources of ERP Package-Organisation Misalignments," Journal of Strategic Information Systems (13:4 SPEC. ISS.), pp. 375-397.

Stoel, D. M., and Muhanna, W. A. 2012. "The Dimensions and Directionality of Trust and Their Roles in the Development of Shared Business-IS Understanding," Information and Management (49:5), pp. 248-256.

Ullah, A., and Lai, R. 2013. "A Systematic Review of Business and Information Technology Alignment," ACM Transactions on Management Information Systems (4:1), pp. 1-30.

UN. 2008. "International Standard Industrial Classification of All Economic Activities (ISIC), Rev.4," New York.

Veer Ramjeawon, P., and Rowley, J. 2017. "Knowledge Management in Higher Education Institutions: Enablers and Barriers in Mauritius," Learning Organization (24:5), pp. 366-377.

Wang, J., and Rusu, L. 2018. "Factor Hindering Business-IT Alignment in Small and Medium Enterprises in China," Procedia Computer Science (138), pp. 425-432.

Wei, H. L., Wang, E. T. G., and Ju, P. H. 2005. "Understanding Misalignment and Cascading Change of ERP Implementation: A Stage View of Process Analysis," European Journal of Information Systems (14:4), pp. 324-334.

Weiss, J. W., and Anderson, D. 2004. "Aligning Technology and Business Strategy: Issues \& Frameworks, A Field Study of 15 Companies," in Proceedings of the 37th Hawaii International Conference on System Sciences - 2004, pp. 1-10.

Willson, P., and Pollard, C. 2009. "Exploring IT Governance in Theory and Practice in a Large MultiNational Organisation in Australia," Information Systems Management (26:2), pp. 98-109.

Wong, W. N. Z. 2009. "The Strategic Skills of Business Continuity Managers: Putting Business Continuity Management into Corporate Long-Term Planning," Journal of Business Continuity \& Emergency Planning (4:1), pp. 62-68.

Yin, R. K. 1984. Case Study Research: Design and Methods, Thousand Oaks, California: Sage Publications.

\section{How to cite:}

Sundoro, H. S. and Wandebori, H. 2021. "Exploring the Misalignment between Business and Information Technology on the Implementation of Balanced Scorecard: Case Study of State-Owned Telecommunication Companies in Indonesia," Jurnal Sistem Informasi (Journal of Information System) (17:2), pp. 18-32. 